\title{
Effect of Agenesis on the Crown-Size Profile Pattern
}

STANLEY M. GARN and ARTHUR B. LEWIS

Center for Human Growth and Development, University of Michigan, Ann Arbor, Michigan, and Fels Research Institute, Yellow Springs, Ohio 48104

Agenesis and hypodontia are associated with crown-size reduction in the remaining teeth (S. M. GARN ET AL, J Dent Res 41:717, 1962, Nature 200:488-489, 1963; J Dent Res 42:13441363, 1963; H. J. KEENE, Amer J Orth 50: 445-451, 1964; and K. HaNLHARA ET AL, $J$ Anthrop Soc Nippon 73:72-81, 1965). The question arises as to whether crown-size reduction associated with tooth number reduction is uniform throughout the remaining teeth or whether there is differential reduction in tooth material that results in a distinctly different crown-size profile pattern.

In order to answer this question we measured the mesiodistal crown diameters of 658 subjects, including 82 with third molar agenesis and 19 with radiographically verified agenesis of multiple teeth. The original measurements were converted into sex-specific $t$-scores using a computer program (C. R. BLACK, Ann NY Acad Sci 134:538-540, 1966). The crown-size profile patterns were then compared using the statistic $r_{T}$ as previously described (S. M. GARN ET AL, J Dent Res 47:1190, 1968: Arch Oral Biol 13:1235-1242, 1968: Amer Anthrop 71: 79.84, 1969).

As shown in the table, the crown-size profile pattern of individuals lacking one or more mandibular third molars is distinctly different from that of the total group $(r=-0.34)$. Sim-

This work was supported by USPHS Research Grants DE-01294 and FR-00222 from the National Institutes of Health, Bethesda, Md.

Additional information available on request to authors.

Received for publication March 4, 1969.
TABLE

Crown-size Profile Pattern Similarities $\left(r_{T}\right)$ OF SUbJects WITH VARYING DegREES OF HYPODONTIA

\begin{tabular}{lc}
\hline \hline Comparison & $r T^{*}$ \\
\hline Third molar agenesis vs & -0.340 \\
$\quad$ total sample & -0.381 \\
$\begin{array}{l}\text { Multiple agenesis vs } \\
\text { total sample }\end{array}$ & \\
$\begin{array}{l}\text { Third molar agenesis vs } \\
\text { multiple agenesis }\end{array}$ & +0.712 \\
\hline
\end{tabular}

* Based on 14 pairs of teeth, calculated from mean value of $T$, see references.

ilarly the crown-size profile pattern of individuals with multiple agenesis differs from that of the total group $(r=-0.38)$. However the crown-size profile patterns of the two agenesis groups strongly resemble each other $(r=+0.71)$. Accordingly, agenesis is associated with differential crown reduction and is characterized by a distinctively different crown-size profile pattern.

Under these circumstances it is of interest to measure changes in the crown-size profile pattern in Down's syndrome (trisomy $G$ ) and other chromosomal abnormalities such as ring $D$, and in deletions and reduplications of the sex chromosomes. Further, alterations in the crown-size profile patterns in relatives of subjects with cleft palate would help to identify genetic carriers of this complex developmental abnormality. 